\title{
Quantitative evaluation of free gas and adsorbed gas content of Wufeng-Longmaxi shales in the Jiaoshiba area, Sichuan Basin, China
}

\author{
Qiyang Gou, Shang $\mathrm{Xu}^{\circledR *}$ \\ Key Laboratory of Tectonics and Petroleum Resources, Ministry of Education, \\ China University of Geosciences, Wuhan 430074, P. R. China
}

(Received May 6, 2019; revised June 5, 2019; accepted June 11, 2019; available online June 16, 2019)

\section{Citation:}

Gou, Q., Xu, S. Quantitative evaluation of

free gas and adsorbed gas content of Wufeng-Longmaxi shales in the Jiaoshiba area, Sichuan Basin, China. Advances in Geo-Energy Research, 2019, 3(3):

258-267, doi: 10.26804/ager.2019.03.04.

Corresponding author:

*E-mail: xushang0222@163.com

\section{Keywords:}

Shale gas

free gas

adsorbed gas

gas content

isothermal adsorption

Jiaoshiba area

\begin{abstract}
:
Quantitative analysis of free gas and adsorbed gas contents in shale reservoirs are great significance for efficient exploration and development of shale gas. Based on the isothermal adsorption experiment of shale samples from Wufeng-Longmaxi Formation of JYA well in Jiaoshiba area and Langmuir volume model, the relationship between shale adsorption capacity and temperature, pressure, organic carbon content, quartz and clay mineral content is analyzed. Besides, the key parameters such as Langmuir volume and Langmuir pressure are dynamically calibrated by combining grey correlation method. A new model for calculating adsorbed gas and free gas is established, which takes fully into account the formation temperature, pressure, total organic carbon and shale mineral components. The results showed that the gas content of shale calculated by the new dynamic modified model is in good agreement with the actual gas content characteristics of shale reservoirs. The new model fully takes into account the vertical and horizontal heterogeneity of mineral components and its influence on shale adsorption capacity. That is not only suitable for the tectonic stability area but also for the gas content analysis in the area with strong tectonic movement. It is concluded that the modified calculation model can effectively predict the adsorbed gas, free gas and total gas content of shale reservoirs under formation conditions, which can be used as an indicator for the analysis and prediction of the exploration and development potential of shale gas wells.
\end{abstract}

\section{Introduction}

Shale gas, a typical unconventional natural gas of selfgeneration and self-storage (Curtis, 2002; Hao et al., 2008; Hao et al., 2013a; Cai et al., 2018, 2019), mainly stores in the surface of kerogen and clay particles as adsorbed gas, and aggregates in natural fractures and nano-micron pores as free gas. In addition, a very small amount of gas stores in "in-situ" liquid and formation water as dissolved gas. During the accumulation of shale gas, the adsorbed gas, free gas and dissolved gas are in a certain dynamic equilibrium system. However, when the temperature, pressure and other conditions changed, they can be transformed into each other (Wang et al., 2011; Hao et al., 2013b; Jiang et al., 2018). Especially, the free gas content is the key factor to determine the high yield and final recovery of shale gas wells (Hao et al., 2013b; Wang et al., 2013). The adsorbed gas content directly affects the economic recoverable value and continuous production time of the shale gas wells (Jiang et al., 2018). Nevertheless, the dissolved gas content is small in shale reservoirs, which can be ignored (Wang et al., 2011; Jiang et al., 2018). Therefore, the systematic analysis of free gas and adsorbed gas content in shale reservoirs is great practical significance for the efficient exploration and development of shale gas.

The quantitative characterization methods of free gas and adsorbed gas in shale reservoirs mainly include the logging interpretation (Tang et al., 2014), nuclear magnetic resonance (NMR) technique ( $\mathrm{Li}$ et al., 2018) and isothermal adsorption method (Li et al., 2012; Zhang et al., 2017). Among which, the isothermal adsorption method is widely used according to combined with Langmuir volume model. However, more and more scholars pointed out that the Langmuir sorption model is a limiting model for low pressures and some features cannot be represented by the simple Langmuir model (Zhang et al., 2017). Therefore, based on the relationships between (a) Langmuir volume vs. total organic carbon (TOC), (b) 


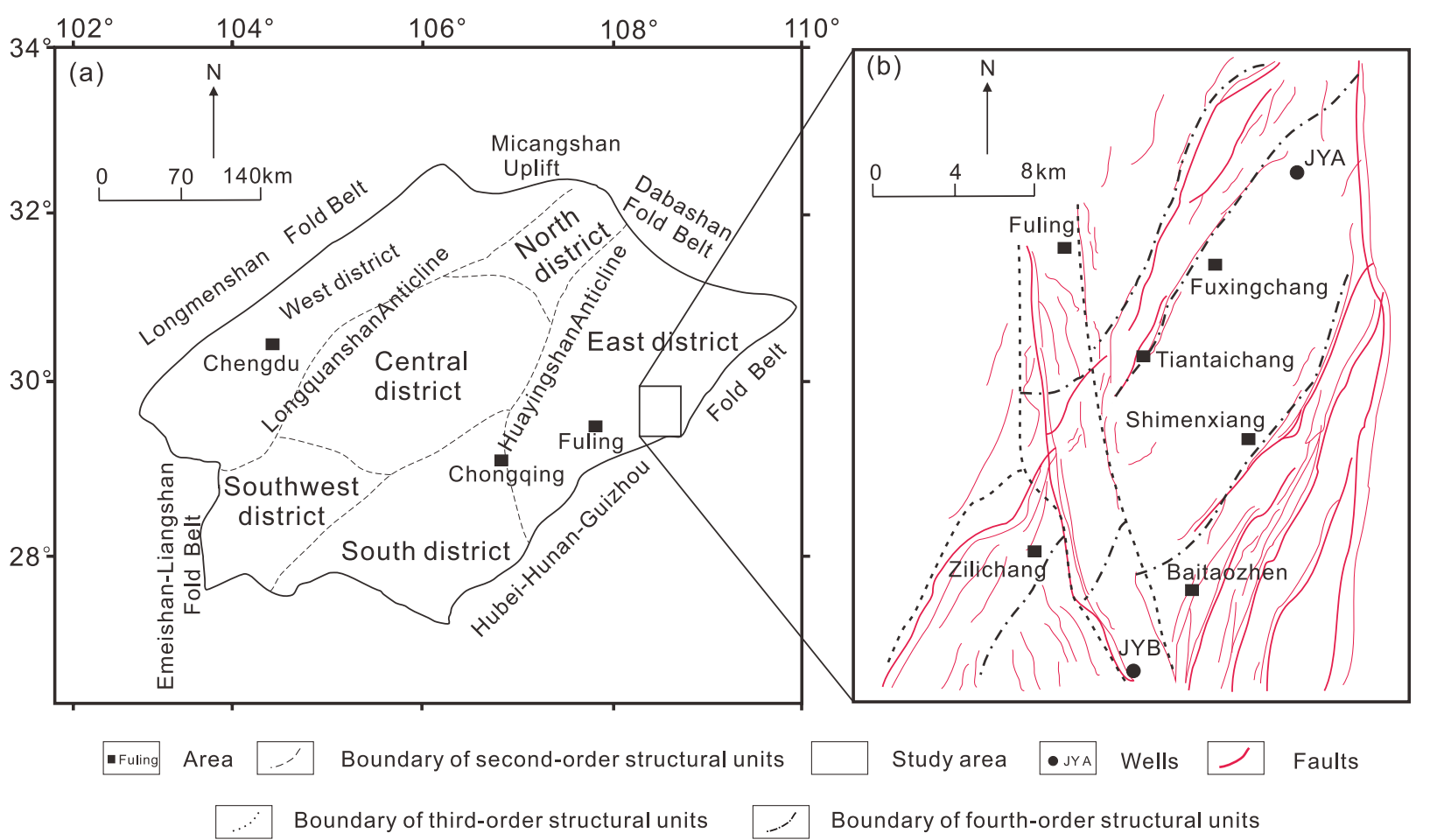

Fig. 1. (a) Location of the study area, modified from Hao et al. (2008); (b) Tectonic map of the Jiaoshiba area, modified from She et al. (2016).

Langmuir volume vs. temperature, and (c) the logarithm of Langmuir pressure vs. temperature, the Langmuir volume model is modified and a lot of works are conducted (Ambrose et al., 2010; Li et al., 2012; Ji et al., 2014; Yang et al., 2015; Yang et al., 2017; Zhang et al., 2017). However, it should be noticed that these studies are mainly focused on analyzing the influence of TOC, temperature and pressure on adsorbed gas or free gas, and the effect of shale mineral components (such as quartz and clay minerals) on the occurrence of shale gas are less discussed (Zhao et al., 2017). In addition, the mineral components of the shale reservoirs are highly heterogeneous in the vertical and horizontal directions. Furthermore, the specific surface areas of different minerals (such as quartz and clay) are quite different, which have obvious difference on shale adsorption capacity (Guo, 2014; Kim et al., 2017; Jiang et al., 2018).

In this study, taking the JYA well in the Jiaoshiba area, Sichuan Basin, as research object, the contribution ratio of TOC, quartz and clay mineral to shale adsorption capacity is firstly conducted by grey correlation method. Moreover, a calculation model of gas content with full consideration of shale mineral composition, TOC and temperature and pressure conditions is established. Finally, the characteristics of free gas and adsorbed gas in different tectonic units are quantitatively evaluated, aiming to provide theoretical basis for shale gas resource potential and exploration and development potential evaluation.

\section{Geological setting and samples}

The Jiaoshiba area, a special normal structure within the intersection of the Wanxian Synclinorium and Fangdoushan Anticlinorium, is located in the east of the Eastern Sichuan Basin boundary fault-west of the Qiyue Mountain fault (Fig. 1a) (Dai et al., 2016; Gou et al., 2018). The study area mainly experienced basement imbricate thrusting, detachment, and left-lateral transpression to form the current anticline structure that is surrounded by faults (Gou et al., 2019a). It is characterized as high buried depth in northeast and low in southwest (She et al., 2016). The main area of Jiaoshiba area, characterized by a box-like with weak deformation and undeveloped faults, is controlled by gentle faulted anticline (Fig. 1b). However, the two wings are featured by steeply dipping and well developed faults (Guo, 2015).

The Longmaxi shales of Jiaoshiba are mainly deposited in the environment of undercompensation and detaining anoxia, as a result, shale lithology is simple and fine (Guo et al., 2016). Based on the characteristics of shales color, mineral composition and biological fossils, the Longmaxi shales are divided from bottom to top into the first member of Longmaxi formation (Long1 shales), the second member of Longmaxi formation (Long2 shales) and the third member of Longmaxi formation (Long3 shales). Moreover, the Wufeng-Long1 shales can be further subdivided into nine layers (1) (9) according to the lithology and electricity characteristics. The WufengLong1 shales are dominated by gray-black carbonaceous radiolarian or graptolite shale and gray-black silty-sand carbonaceous shale, with local thin layers or belts of pyrite and horizontal bedding (Guo, 2016). The brittle mineral contents, such as quartz and feldspar, are as high as $51 \% \sim 83 \%$ with an average of $66 \%$. The TOC is generally larger than $2.0 \%$ 
with an average of $3.5 \%$. The shales are characterized by high to over-maturity stage, with $\mathrm{R}_{\mathrm{o}}$ ranges from $2.2 \% \sim 3.6 \%$, and kerogen is type I (Gou et al., 2019a). The reservoirs contain abundant nano-submicron pores (Guo, 2016; Guo et al., 2016). Previous studies have shown that the carbon isotopes compositions of methane, ethane and propane of the Wufeng-Long 1 shales are completely inverted (i.e. $\delta^{13} \mathrm{C}_{1}$ $>\delta^{13} \mathrm{C}_{2}>\delta^{13} \mathrm{C}_{3}$ ), the gas content ranges from 0.13 to 6.5 $\mathrm{m}^{3} / \mathrm{t}$ and generally greater than $3.5 \mathrm{~m}^{3} / \mathrm{t}$, which is the main strata of shale gas exploration and development (Guo, 2015, 2016; Gou et al., 2019b).

A total of 13 shale core samples were collected from JYA well (7 samples) and JYB well (6 samples), Jiaohiba area, Sichuan Basin. The locations of wells were shown in Fig. 1b. All the shale samples were conducted to organic geochemistry analysis, mineral composition, gas content and porosity testing. The detailed experimental procedures were described by Ma et al. (2015).

\section{Calculation model of shale gas in different occurrence states}

\subsection{Calculation model of adsorbed gas and calibra- tion of key parameters}

The Langmuir model assumes that the gas adsorption follows the monolayer adsorption theory (Langmuir, 1918). Under a certain temperature, the methane adsorption capacity of the shale is quantitatively calculated by measuring the relationship between the gas molecule adsorption capacity and the pressure on the shale surface.

$$
V=\frac{V_{L} P}{P+P_{L}}
$$

where $V$ is adsorbed gas content, $\mathrm{m}^{3} / \mathrm{t} ; V_{L}$ is Langmuir volume, which represents the maximum gas adsorption capacity at a given temperature, $\mathrm{m}^{3} / \mathrm{t} ; P$ is the gas pressure, $\mathrm{MPa}$; and $P_{L}$ is the Langmuir pressure, which represents the pressure at which the total volume absorbed is equal to one-half of the maximum gas adsorption capacity, MPa.

Eq. (1) shows that shale adsorbed gas content is closely related to Langmuir volume and Langmuir pressure. However, the Langmuir volume and Langmuir pressure do not take into account the variation of the vertical and horizontal directions mineral heterogeneity, temperature and pressure in shale reservoirs (Zhang et al., 2012; Ji et al., 2014; Yang et al., 2015). Therefore, it is necessary to calibrate the parameters when calculating the content of adsorbed gas.

\subsubsection{Calibration of Langmuir volume}

The Langmuir volume is mainly influenced by the contents of TOC, siliceous minerals and clay minerals (Zhang et al., 2012; Zhao et al., 2017). Based on the relationship between Langmuir volume and TOC, quartz and clay, the Langmuir volume calculation equation can be obtained.

$$
V_{L}^{1}=a_{1} \operatorname{Ln}(T O C)+b_{1}
$$

$$
\begin{gathered}
V_{L}^{2}=a_{2} \operatorname{Ln}(\text { Quart } z)+b_{2} \\
V_{L}^{3}=a_{3} \operatorname{Ln}(\text { Clay })+b_{3}
\end{gathered}
$$

where $V_{L}^{1}$ is Langmuir volume calibrated by TOC, $\mathrm{m}^{3} / \mathrm{t} ; V_{L}^{2}$ is Langmuir Volume calibrated by quartz, $\mathrm{m}^{3} / \mathrm{t} ; V_{L}^{3}$ is Langmuir Volume calibrated by clay, $\mathrm{m}^{3} / \mathrm{t}$; TOC is shale organic carbon content, \%; Quartz is quartz content, \%; Clay is clay content, $\% ; a_{1}, a_{2}, a_{3}, b_{1}, b_{2}$ and $b_{3}$ are calibration coefficient, respectively.

Due to the large difference of the surface areas of organic matter, quartz and clay minerals, which can affect the adsorption capacity on varying degrees (Chalmers and Bustin, 2007; Gasparik et al., 2014; Tang et al., 2016; Qi et al., 2019). According to the principles of standardization, integrity and similarity, the correlation between each influence factor and the target system can be quantitatively calculated by combined with the grey relational theory (Gou et al., 2019b). In other words, the contribution of each influence factor to the target system can be calculated. Based on the grey relational theory, the Langmuir volume dynamic correction model is established in this study.

$$
V_{L C}=a_{4} V_{L}^{1}+a_{5} V_{L}^{2}+a_{6} V_{L}^{3}
$$

where $V_{L C}$ is Langmuir volume of dry shale samples calibrated by TOC, quartz and clay minerals, $\mathrm{m}^{3} / \mathrm{t} ; a_{4}, a_{5}$ and $a_{6}$ are the contribution values of TOC, quartz and clay minerals to the Langmuir volume, respectively, and the detailed calculation process can be referred to Gou et al. (2019b).

\subsubsection{Calibration of Langmuir pressure}

Previous studies have shown that there is an obvious linear relationship between the natural logarithm of Langmuir pressure and the reciprocal of temperature (Ambrose et al., 2010; Li et al., 2012; Ji et al., 2014; Yang et al., 2015; Zhang et al., 2017). Therefore, according to the Langmuir pressure obtained by JYA well shale samples at $30{ }^{\circ} \mathrm{C}$ and $85^{\circ} \mathrm{C}$ (close to the actual formation temperature), the dynamic calibration model between Langmuir pressure and temperature can be established by least square method.

$$
P_{L C}=\exp \left(\frac{a_{7}}{t+273.15}+b_{4}\right)
$$

where

$$
t=t_{0}+\frac{t_{G} h}{100}
$$

where $P_{L C}$ is Langmuir pressure calibrated by temperature, $\mathrm{MPa} ; t$ is actual formation temperature, ${ }^{\circ} \mathrm{C}$; $t_{0}$ is surface temperature, ${ }^{\circ} \mathrm{C} ; t_{G}$ is geothermal gradient, ${ }^{\circ} \mathrm{C} / 100 \mathrm{~m} ; h$ is burial depth of shale samples, $\mathrm{m} ; a_{7}$ and $b_{4}$ are Langmuir pressure calibration coefficient, respectively. The surface temperature of Jiaoshiba area is about $20{ }^{\circ} \mathrm{C}$ (Zhao et al., 2017), and the temperature gradient is about $2.83{ }^{\circ} \mathrm{C} / 100 \mathrm{~m}$ (Guo, 2014). 


\subsubsection{Calibration of adsorbed gas content}

Based on the calibrated Langmuir volume and Langmuir pressure, combined with the actual formation pressure (Eq. (8)), the adsorbed gas content of dry shale samples under formation conditions can be calculated.

$$
\begin{gathered}
P_{F}=P_{G} \rho_{w} g h \times 10^{-6} \\
V_{A}=\frac{V_{L C} P_{F}}{P_{F}+P_{L C}}
\end{gathered}
$$

where $P_{F}$ is actual formation pressure, $\mathrm{MPa} ; P_{G}$ is formation pressure coefficient; $\rho_{w}$ is formation water density, $\mathrm{kg} / \mathrm{m}^{3} ; g$ is gravity acceleration, $\mathrm{N} / \mathrm{kg} ; V_{A}$ is adsorption gas content of dry shale samples under formation conditions, $\mathrm{m}^{3} / \mathrm{t}$. The formation pressure coefficient of JYA well in Jiaoshiba area is about 1.55 (Jin et al., 2018).

However, in the actual formation conditions, the shale reservoirs contain a certain amount of bound water. Hence, it is necessary to calibrate the adsorption gas content of dry samples with equilibrium water. Guo (2014) according to the methane isothermal adsorption experiment of dry shale samples and equilibrium water samples at $85^{\circ} \mathrm{C}$ in Jiaoshiba area, the characteristics of equilibrium water samples adsorbed gas under formation temperature $\left(85^{\circ} \mathrm{C}\right)$ and pressure conditions in the study area are obtained.

$$
V_{A}^{*}=0.8281 V_{A}+0.1469
$$

where $V_{A}^{*}$ is adsorbed gas content of equilibrium water samples in formation conditions, $\mathrm{m}^{3} / \mathrm{t}$.

\subsection{Calculation model of free gas and calculation of key parameters}

Free gas can flow freely in the connected pore-fracture system, which is easier to produce than adsorbed gas. The content of free gas is mainly affected by shale porosity, water saturation, temperature, pressure and preserve conditions and so on (Hao et al., 2013b; Guo, 2014; Jiang et al., 2018). Therefore, it can be characterized by porosity, gas compression coefficient (affected by formation temperature and pressure) and water/gas saturation (Lewis et al., 2004).

$$
V_{F}=\frac{\phi S_{G}}{B_{G} \rho_{F}}
$$

where $V_{F}$ is free gas content, $\mathrm{m}^{3} / \mathrm{t} ; \phi$ is effective porosity of shale samples, which is tested by helium pycnometry; $S_{G}$ is effective gas saturation of shale samples; $B_{G}$ is volume coefficient of natural gas, $\mathrm{m}^{3} / \mathrm{m}^{3} ; \rho_{F}$ is bulk density of shale samples, which is tested by helium pycnometry, $\mathrm{g} / \mathrm{cm}^{3}$.

Since adsorbed gas is enriched on the surface of shale pores and the storage spaces of free gas are occupied, this section of pore spaces should be removed when calculating the content of free gas (Ambrose et al., 2010).

$V_{F}=\frac{32.0368 \times 0.0283168}{B_{G}}\left[\frac{\phi\left(1-S_{W}\right)}{\rho_{F}}-\frac{1.318 \times 10^{-6} M V_{A}}{\rho_{s}}\right]$

where $M$ is apparent relative molecular weight of natural gas, $\mathrm{g} / \mathrm{mol} ; \rho_{s}$ is density of adsorbed phase natural gas, which is ranges from 0.37 to $0.43, \mathrm{~g} / \mathrm{cm}^{3} ; S_{W}$ is water saturation of shale samples. In accordance with the previous works, $M=16$ and $\rho_{s}=0.37$ are applied in this study (Haydel and Kobayashi, 1967; Ambrose et al., 2010).

\subsubsection{Calculation of volume coefficient}

The natural gas volume coefficient refers to the volume ratio of certain amount of natural gas under formation conditions to it under standard conditions $\left(20^{\circ} \mathrm{C}, 0.101325 \mathrm{MPa}\right)$ ( $\mathrm{Li}, 2015)$, the equation of which is as follows:

$$
B_{G}=\frac{V_{G}}{V_{S C}}
$$

where $V_{G}$ is natural gas volume under formation conditions, $\mathrm{m}^{3} ; V_{S C}$ is natural gas volume under standard conditions, $\mathrm{m}^{3}$.

Under surface ground conditions, the temperature and pressure are relatively low, molecular diameter is much smaller than intermolecular distance, resulting in weaker intermolecular force, and the gas volume approximately satisfies the ideal gas equation (Eq. (14)). However, in the actual reservoirs, especially the Wufeng-Longmaxi shale in the Jiaoshiba area belongs to the high-temperature and high-pressure gas-rich reservoirs, and the intermolecular force is relatively large (Guo, 2014), Therefore, the gas equation should be calibrated (Eq. (15)).

$$
\begin{gathered}
V_{S C}=\frac{n R\left(t_{0}+273\right)}{P_{S C}} \\
V_{G}=\frac{Z n R(t+273)}{P_{F}}
\end{gathered}
$$

where $Z$ is compressibility factor of natural gas; $n$ is amount of substance, mol; $R$ is the universal gas constant, $\mathrm{MPa} \cdot \mathrm{m}^{3} /(\mathrm{kmol} \cdot \mathrm{K}) ; P_{S C}$ is pressure under standard conditions, $0.101325 \mathrm{MPa}$.

The compressibility factor of natural gas indicates the degree of difficulty of compression of real gas relative to ideal gas ( $\mathrm{Li}, 2015)$. At present, the method of Standing and Katz (1942) is commonly used to obtain compressibility factor. Its application range is as follows: the apparent corresponding pressure $\left(P_{p r}\right)$ of natural gas is range from 0 to 15 , and the corresponding temperature $\left(T_{p r}\right)$ of natural gas is range from 1.05 to 3.0. That is, the corresponding pressure is $0 \sim 69.06$ $\mathrm{MPa}$ and the temperature is $-42.93 \sim 364.35{ }^{\circ} \mathrm{C}$. Based on Eqs. (7) and (8), the pressure and temperature of the shale samples in study area are $35.4 \sim 36.68 \mathrm{MPa}$ and $85.95 \sim 88.34$ ${ }^{\circ} \mathrm{C}$, respectively. Therefore, the SK method can be used to calculate the compressibility factor. The equation of apparent 
corresponding pressure and apparent corresponding temperature are as follow:

$$
\begin{gathered}
P_{p r}=\frac{P_{F}}{P_{p c}} \\
T_{p r}=\frac{t+273}{T_{p c}}
\end{gathered}
$$

where $P_{p c}$ is the apparent corresponding pressure of natural gas, methane is about $4.604, \mathrm{MPa} ; T_{p c}$ is the corresponding temperature of natural gas, methane is about 190.55 , K.

Combined Eq. (16) and Eq. (17), the apparent corresponding pressure and the apparent corresponding temperature of shale samples are calculated to be 7.69 7.97 (average 7.82) and 1.88 1.9 (average 1.89), respectively. As a result, the compressibility factor of shale gas identified on the SK chart is about 1.05 .

\subsubsection{Calculation of water saturation}

In general, based on rock resistivity, effective porosity and formation water resistivity, the water saturation can be calculated using the Archie formula (Zhao et al., 2007; Tang et al., 2014). However, since the Archie formula is based on the pure sandstone formation model, which means that the rock skeleton is not conductive. Therefore, it is not suitable for the calculation of water saturation in shale reservoirs (Jiang et al., 2018). The Simandoux formula is widely used in the calculation of shale reservoirs water saturation because it takes into account the shale content and resistivity (Jiang et al., 2018).

$$
S_{W}=\sqrt[n]{\frac{a R_{W}\left(1-V_{s h}\right)^{m-1}}{(n-1) R_{t} \phi^{m}}}
$$

where $a$ is the proportionality coefficient; $m$ is the rock cementation coefficient; $n$ is saturation exponent; $R_{W}$ is formation water resistivity, $\Omega \cdot \mathrm{m} ; R_{t}$ is formation resistivity, $\Omega \cdot \mathrm{m} ; V_{s h}$ is shale content. According to the actual data of logging in Jiaoshiba area, Guo (2014) has identified $a=1.05, m=1.53$, $n=1.92$, and the average formation water resistivity is about $0.05 \Omega \cdot \mathrm{m}$.

\subsubsection{Calibration of free gas content}

Eq. (12) shows that the actual free gas content needs to be calibrated by the adsorbed gas content of the equilibrium water samples under the formation conditions. Combined with the natural gas volume coefficient, compressibility factor, water saturation and others relevant parameters, the calculation model of free gas content in equilibrium water samples under formation conditions is established.

$$
\begin{aligned}
V_{F}^{*} & =\frac{32.0368 \times 0.0283168}{3.631 \times 10^{-4} \times \frac{t+273}{P_{F}}}\left[\frac{\phi}{\rho_{F}}\left(1-\sqrt[n]{\frac{a R_{W}\left(1-V_{s h}\right)^{m-1}}{(n-1) R_{t} \phi^{m}}}\right)\right. \\
& \left.-\frac{1.318 \times 10^{-6} M V_{A}^{*}}{\rho_{s}}\right]
\end{aligned}
$$

where $V_{F}^{*}$ is free gas content of equilibrium water samples in formation conditions, $\mathrm{m}^{3} / \mathrm{t}$.

\section{Analysis of gas content calculation model and its application}

\subsection{Quantitative calculation of shale gas in different occurrence states}

\subsubsection{Quantitative calculation of adsorbed gas content}

Mineralogy composition of the shale samples from the Wufeng-Longmaxi formation of JYA well are illustrated in Table 1. Quartz content ranges from $25.2 \%$ to $42.7 \%$, with an average of $34.3 \%$. The clay minerals content ranges between $35.1 \%$ and $62.6 \%$, with an average of $44.5 \%$. In general, quartz content of these shales decreases from bottom to top formation while the clay minerals content shows a reverse tendency (Table 1). Therefore, the selected samples can represent the vertical characteristics of shale mineral components.

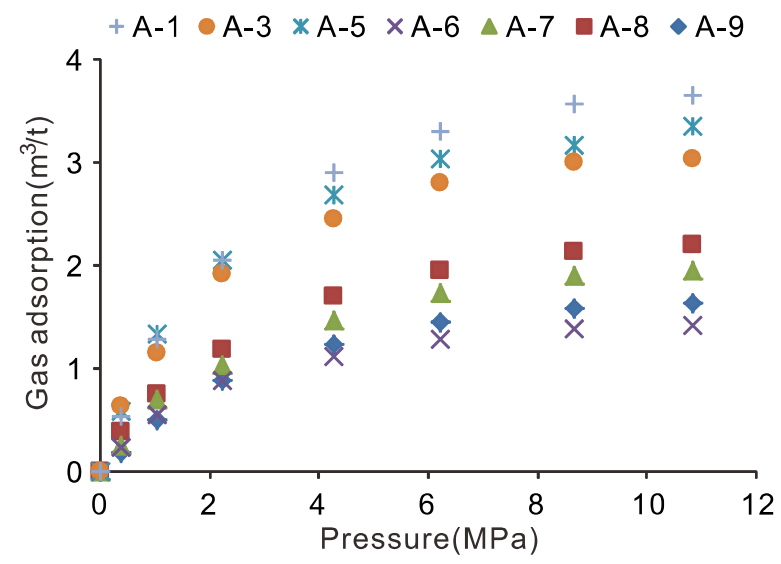

(a)

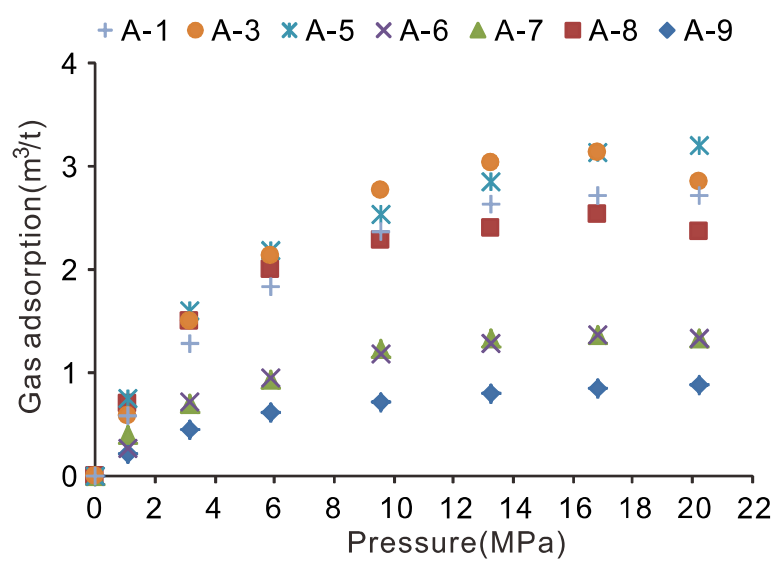

(b)

Fig. 2. Methane sorption isotherms for JYA well shale samples at $30{ }^{\circ} \mathrm{C}$ (a) and $85{ }^{\circ} \mathrm{C}$ (b). 
Table 1. TOC, porosity and mineralogical compositions of shale samples in JYA well.

\begin{tabular}{llllll}
\hline Sample ID & Depth $(\mathrm{m})$ & Quartz $(\%)$ & Clay $(\%)$ & TOC $(\%)$ & Porosity $(\%)$ \\
\hline A-9 & 2,330 & 25.2 & 62.6 & 1.11 & 5.09 \\
A-8 & 2,347 & 32.3 & 38.3 & 2.68 & 4.68 \\
A-7 & 2,355 & 33.9 & 43.2 & 1.62 & 3.59 \\
A-6 & 2,376 & 31.1 & 44.7 & 1.83 & 3.97 \\
A-5 & 2,385 & 42.2 & 38.5 & 3.59 & 3.83 \\
A-3 & 2,397 & 42.7 & 35.1 & 3.46 & 4.51 \\
A-1 & 2,415 & 32.8 & 49.1 & 4.45 & 4.47 \\
\hline
\end{tabular}

Table 2. Langmuir fitting results of methane adsorption in JYA well shale samples.

\begin{tabular}{lllll}
\hline Sample ID & Depth $(\mathrm{m})$ & Temperature $\left({ }^{\circ} \mathrm{C}\right)$ & Langmuir volume $\left(\mathrm{m}^{3} / \mathrm{t}\right)$ & Langmuir pressure $(\mathrm{MPa})$ \\
\hline A-9 & 2,330 & 85 & 1.06 & 4.29 \\
A-8 & 2,347 & 85 & 2.82 & 2.65 \\
A-7 & 2,355 & 85 & 1.64 & 3.71 \\
A-6 & 2,376 & 85 & 1.73 & 4.87 \\
A-5 & 2,385 & 85 & 3.95 & 4.75 \\
A-3 & 2,397 & 85 & 3.85 & 4.86 \\
A-1 & 2,415 & 85 & 3.54 & 5.30 \\
\hline
\end{tabular}

In addition, the shale samples have TOC and helium porosity ranging from $1.11 \%$ to $4.45 \%$, and from $3.59 \%$ to $5.09 \%$, with an average of $2.68 \%$ and $4.31 \%$, respectively (Table 1 ).

Based on the Langmuir isothermal adsorption model, the selected seven shale samples of JYA well are tested at 30 ${ }^{\circ} \mathrm{C}$ and $85{ }^{\circ} \mathrm{C}$, respectively (Fig. 2). The results showed that when the test temperature was $85{ }^{\circ} \mathrm{C}$, the Langmuir volume ranges from 1.06 to $3.95 \mathrm{~m}^{3} / \mathrm{t}$, with an average of $2.66 \mathrm{~m}^{3} / \mathrm{t}$. Among which, the proportion of samples with gas content above $2 \mathrm{~m}^{3} / \mathrm{t}$ is about $57.14 \%$, which shows that the shales adsorption capacity of the study area is relatively strong (Table 2). The Langmuir pressure ranges from 2.65 to $5.3 \mathrm{MPa}$, with an average of $4.35 \mathrm{MPa}$, which indicates that the shales adsorption volume increases greatly in the low pressure section (Fig. 2b).

On the other hand, according to the vertical variation of TOC, quartz and clay mineral content (Fig. 3), the Langmuir volume, calibrated by TOC and mineral composition, respectively, is obtained (Fig. 4). On this basis, the contribution of TOC, quartz and clay minerals to Langmuir volume are calculated to be $0.44,0.30$ and 0.26 , respectively, based on grey correlation method (Gou et al., 2019b). Furthermore, the total calibrated Langmuir volume is calculated to be $1.03 \sim 3.62 \mathrm{~m}^{3} / \mathrm{t}$ (Eq. (5)) (Table 3). At the same time, the Langmuir pressure of all shale samples at different temperatures is fitted by least square method (Eqs. (6) and (7)), and the calibrated Langmuir pressure expression of the study area is obtained as follows:

$$
P_{L C}=\exp \left(\frac{-985.82}{t+273.15}+4.1999\right)
$$

The actual formation temperature (Eq. (7)) is substituted into Eq. (20) and the calibrated Langmuir pressure is calculated to be 4.28 4.36 $\mathrm{MPa}$ (Table 3). Combined with calibrated Langmuir volume, Langmuir pressure (Table 3) and formation temperature (Eq. (7)) and pressure (Eq. (8)), the adsorbed gas content of dry shale samples under formation conditions is calculated to be $0.92 \sim 3.24 \mathrm{~m}^{3} / \mathrm{t}$ (Eq. (9)), with an average of $2.37 \mathrm{~m}^{3} / \mathrm{t}$ (Fig. 3). However, the adsorbed gas content of the equilibrium water samples is about $0.90 \sim 2.83$ $\mathrm{m}^{3} / \mathrm{t}$ (Eq. (10)), with an average of $2.11 \mathrm{~m}^{3} / \mathrm{t}$ (Fig. 3).

\subsubsection{Quantitative calculation of free gas content}

Based on the Simandoux formula (Eq. (18)), the water saturation of the shale samples is calculated to be $29.46 \% \sim 48.61 \%$, with an average of $38.58 \%$ (Table 3). Hence, combined with Eq. (8), Eq. (19) and adsorbed gas content of equilibrium water samples (Fig. 3), the free gas content of equilibrium water samples under formation conditions is calculated to be $2.16 \sim 3.01 \mathrm{~m}^{3} / \mathrm{t}$, with an average of $2.52 \mathrm{~m}^{3} / \mathrm{t}$ (Fig. 3).

\subsection{Evaluation of gas content calculation model}

The total shale gas content can be characterized by free gas and adsorbed gas because the dissolved gas content in shale reservoirs is small or even negligible (Curtis, 2002; Hao et al., 2013a).

$$
V_{t}=V_{A}+V_{F}
$$

where $V_{t}$ is total shale gas content of shale samples, $\mathrm{m}^{3} / \mathrm{t}$.

Using the free gas content and adsorbed gas content 
Gou, Q. and Xu, S. Advances in Geo-Energy Research 2019, 3(3): 258-267

Table 3. Calibration and calculation results of key parameters in JYA well shale samples.

\begin{tabular}{lllll}
\hline Sample ID & Calibrated Langmuir volume $\left(\mathrm{m}^{3} / \mathrm{t}\right)$ & Calibrated Langmuir pressure $(\mathrm{MPa})$ & Volume coefficient & Water saturation $(\%)$ \\
\hline A-9 & 1.03 & 4.28 & 0.00368 & 48.61 \\
A-8 & 2.83 & 4.30 & 0.00366 & 31.66 \\
A-7 & 2.28 & 4.31 & 0.00365 & 30.33 \\
A-6 & 2.22 & 4.33 & 0.00362 & 42.81 \\
A-5 & 3.54 & 4.33 & 0.00361 & 29.46 \\
A-3 & 3.62 & 4.34 & 0.00360 & 40.71 \\
A-1 & 3.08 & 4.36 & 0.00358 & 46.50 \\
\hline
\end{tabular}

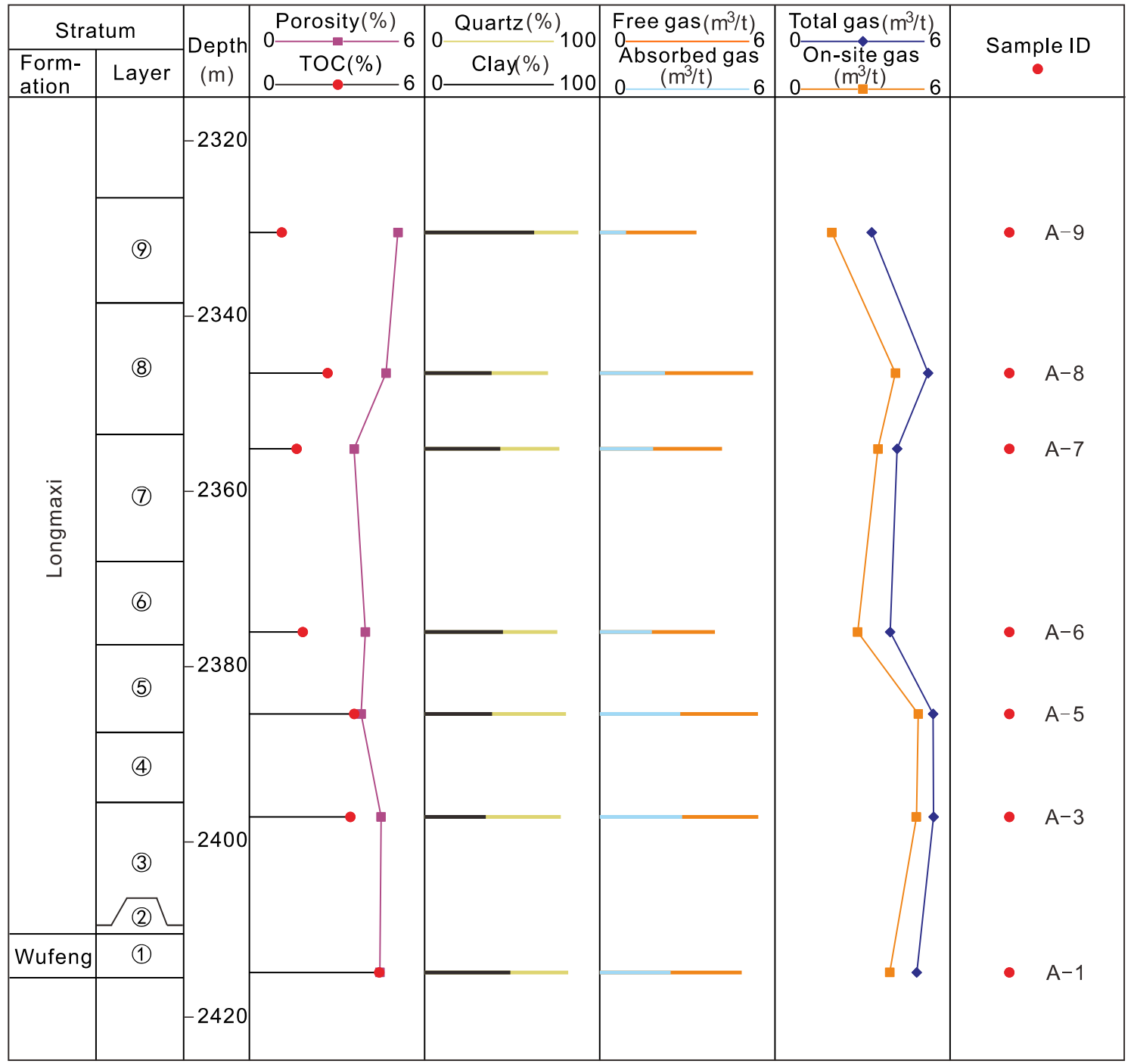

Fig. 3. Methane sorption isotherms for JYA well shale samples at $30^{\circ} \mathrm{C}$ (a) and $85{ }^{\circ} \mathrm{C}$ (b). 


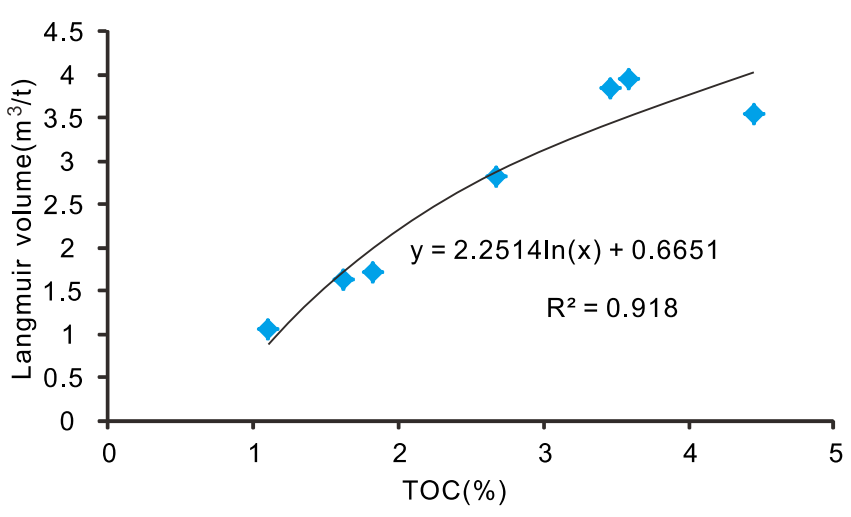

(a)

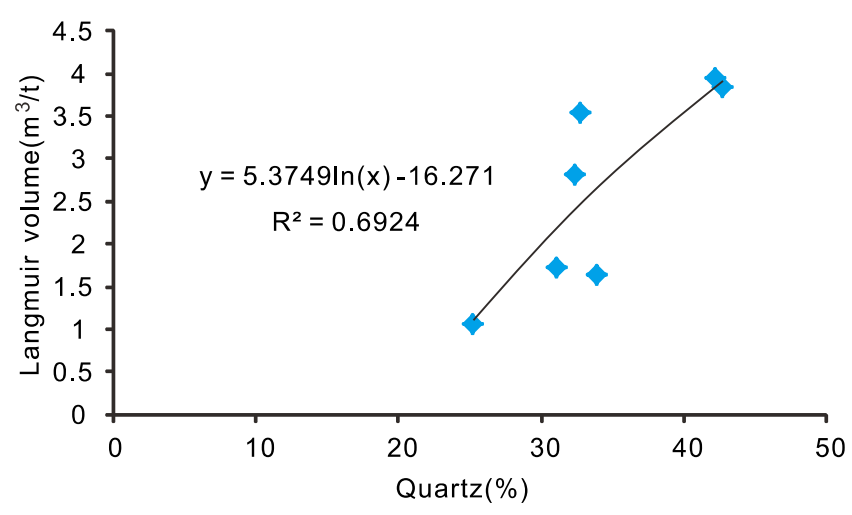

(b)

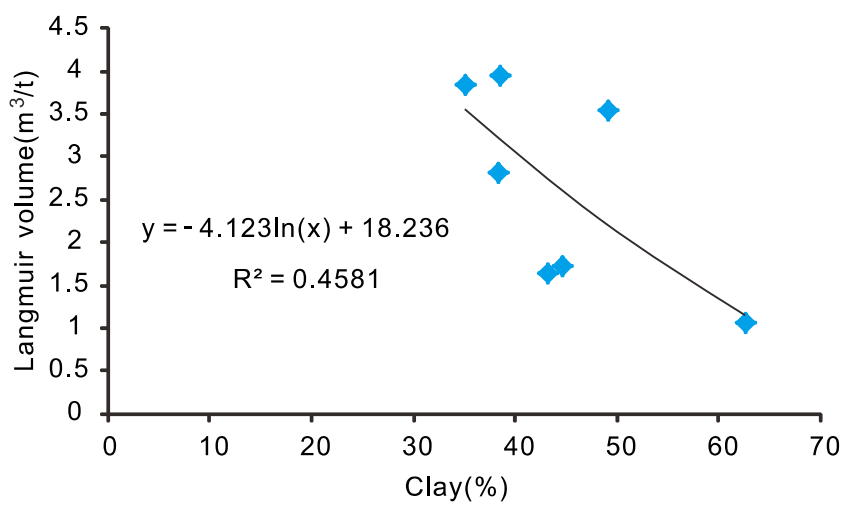

(c)

Fig. 4. The effect of TOC, quartz and clay minerals on Langmuir volume of shale samples in JYA well.

of the equilibrium water samples under formation conditions, the total gas content of the shale samples is calculated to be $3.31 \sim 5.44 \mathrm{~m}^{3} / \mathrm{t}$ (Eq. (21)), with an average of $4.63 \mathrm{~m}^{3} / \mathrm{t}$ (Fig. 3). Among which, the free gas content is $47.98 \% \sim 72.81 \%$ (average 55.46\%), and the adsorbed gas content is $27.19 \% \sim 52.02 \%$ (average $44.54 \%$ ). The calculated total gas content $\left(3.31 \sim 5.44 \mathrm{~m}^{3} / \mathrm{t}\right)$ is slightly different from the on-site gas content $\left(1.95 \sim 4.91 \mathrm{~m}^{3} / \mathrm{t}\right)$. This may be explained as follows: on-site gas content was quantitatively measured according to pressure-tight and coring technique, so as to obtain the gas bearing characteristics of shale reservoirs (Ma et al., 2014; Jiang et al., 2018). However, Jiaoshiba area is characterized by large pressure coefficient and high free gas content. Therefore, it is inevitable that part of the gas will escape during the process of drilling and coring, which will lead to lower on-site gas content (Guo, 2014; Zhang et al., 2017). In addition, although the calculated shale gas content has a deviation from the on-site gas content to some extent, both have the same trend of change (Fig. 3). That is, when the field gas content is large, the calculated shale gas content is also high, which reflects the reliability of the shale gas content calculation model.

In order to further verify the applicability of this model, the shale gas content of another key well (JYB well) with strong tectonic movement in study area is calculated. The results showed that the shale gas content of JYB well is 3.26 4.38 $\mathrm{m}^{3} / \mathrm{t}$ and the corresponding logging interpretation gas content is $3.9 \sim 5.35 \mathrm{~m}^{3} / \mathrm{t}$ (Fig. 5). However, logging interpretation gas content does not take into account vertical or lateral variations of mineral components, resulting in larger prediction results than actually (Zhao et al., 2017). Hence, the calculated results are more consistent with the actual results. The comprehensive analysis shown that the calculation model of adsorbed gas and free gas, which takes fully into account the differences of temperature, pressure, TOC, mineral composition and its adsorption capacity, is not only suitable for tectonic stability area, but also suitable for the evaluation of gas content in the area with strong tectonic movement.

\section{Conclusions}

1) Based on methane isothermal adsorption experiment and grey correlation theory, a new model for calculating adsorbed gas and free gas is established. This model takes fully into account the differences of formation temperature, pressure, TOC, mineral composition and its effects on shale adsorption capacity. On this basis, the shale gas content of different tectonic units in Jiaoshiba area could be quantitatively calculated.

2) According to the modified gas content model, it is calculated that the absorbed gas and free gas contents of well JYA are $0.90 \sim 2.83 \mathrm{~m}^{3} / \mathrm{t}$ and $2.16 \sim 3.01 \mathrm{~m}^{3} / \mathrm{t}$, respectively, and the total gas content is $3.31 \sim 5.44 \mathrm{~m}^{3} / \mathrm{t}$, 


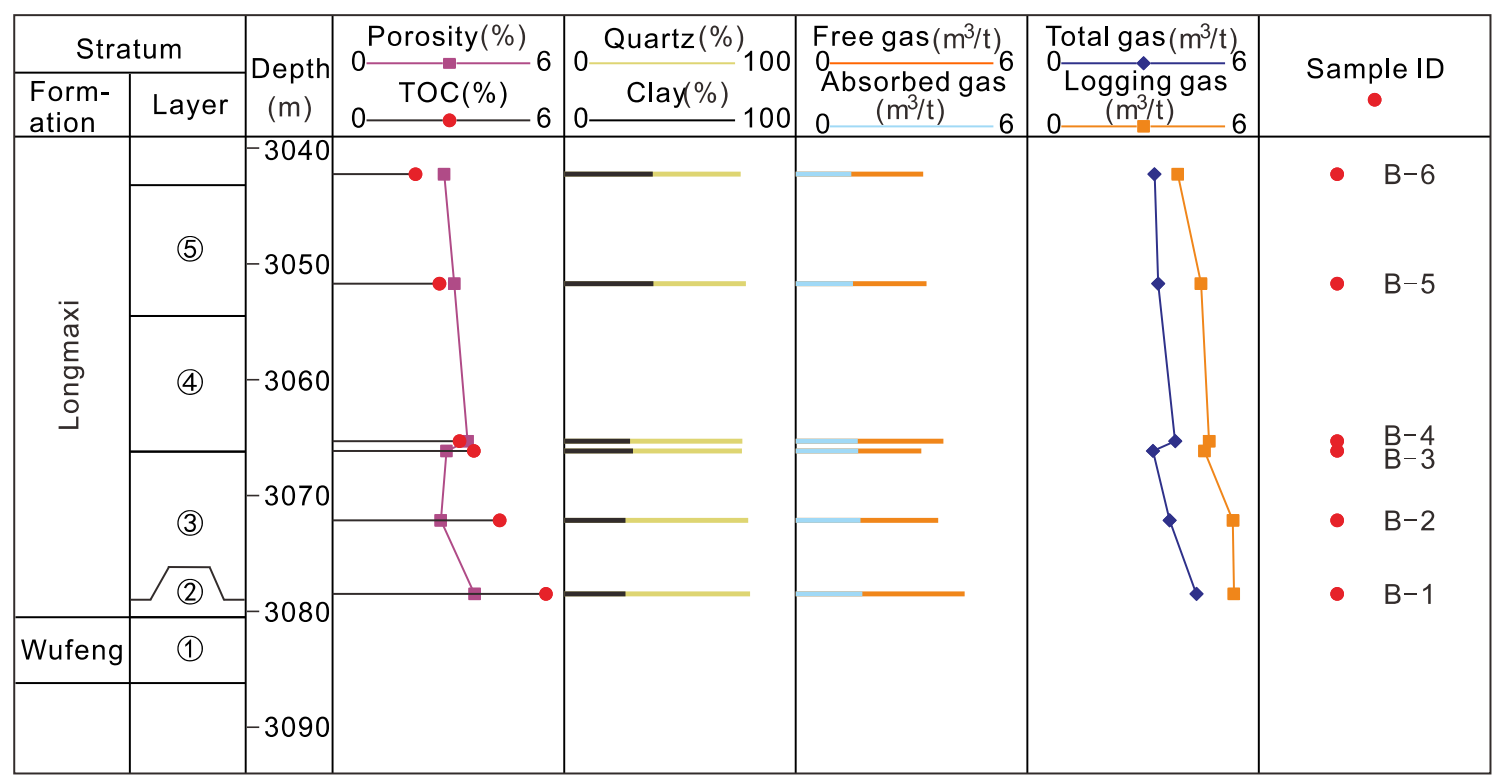

Fig. 5. Geochemical characteristics, mineral composition and gas-bearing of shale samples in JYB well.

with an average of $4.63 \mathrm{~m}^{3} / \mathrm{t}$. It is in good agreement with on-site gas content $\left(1.95 \sim 4.91 \mathrm{~m}^{3} / \mathrm{t}\right)$, which proves the reliability of the new model. In addition, combined with the results of gas-bearing evaluation of another key well in Jiaoshiba area, comprehensive analysis shows that the model is not only suitable for tectonic stability area, but also for gas-bearing analysis in the area with strong tectonic movement. It can be used as an indicator for the evaluation of shale gas resources and exploration and development potential of shale gas wells.

\section{Acknowledgments}

This research was financially funded by the National Natural Science Foundation of China (41690134, 41821002, 41702155, 41690131), National Science \& Technology Specific Project (2016ZX05034002-003).

Open Access This article is distributed under the terms and conditions of the Creative Commons Attribution (CC BY-NC-ND) license, which permits unrestricted use, distribution, and reproduction in any medium, provided the original work is properly cited.

\section{References}

Ambrose, R.J., Hartman, R.C., Campos, M.D., et al. New porescale considerations for shale gas in place calculations. Paper SPE 131772 Presented at the SPE Unconventional Gas Conference, Pittsburgh, Pennsylvania, USA, 23-25 February, 2010.

Cai, J.C., Lin, D.L., Singh, H., et al. Shale gas transport model in 3D fractal porous media with variable pore sizes. Mar. Pet. Geol. 2018, 98: 437-447.

Cai, J.C., Lin, D.L., Singh, H., et al. A simple permeability model for shale gas and key insights on relative importance of various transport mechanisms. Fuel 2019,
252: $210-219$.

Chalmers, G.R.L., Bustin, R.M. The organic matter distribution and methane capacity of the Lower Cretaceous strata of Northeastern British Columbia, Canada. Int. J. Coal Geol. 2007, 70(1-3): 223-239.

Curtis, J.B. Fractured shale-gas systems. AAPG Bull. 2002, 86(11): 1921-1938.

Dai, J.X., Zou, C.N., Dong, D.Z., et al. Geochemical characteristics of marine and terrestrial shale gas in China. Mar. Pet. Geol. 2016, 76: 444-463.

Gasparik, M., Bertier, P., Gensterblum, Y., et al. Geological controls on the methane storage capacity in organic-rich shales. Int. J. Coal Geol. 2014, 123(2): 34-51.

Gou, Q.Y., Xu, S., Hao, F., et al. Characterization method of shale pore structure based on nano-CT: A case study of Well JY-1. Acta Petrolei Sinica 2018, 39(11): 1253-1261. (in Chinese)

Gou, Q.Y., Xu, S., Hao, F., et al. Full-scale pores and microfractures characterization using FE-SEM, gas adsorption, nano-CT and micro-CT: A case study of the Silurian Longmaxi Formation shale in the Fuling area, Sichuan Basin, China. Fuel 2019a, 253: 167-179.

Gou, Q.Y., Xu, S., Hao, F., et al. A comprehensive evaluation index of gas-bearing property of shale reservoirs based on grey relation and its application: A case study of Jiaoshiba area, Sichuan Basin. Natural Gas Geoscience 2019b, 30(7): 1045-1052. (in Chinese)

Guo, T.L. The Fuling Shale Gas Field-A highly productive Silurian gas shale with high thermal maturity and complex evolution history, southeastern Sichuan Basin, China. Interpretation 2015, 3(2): 25-34.

Guo, T.L. Discovery and characteristics of the Fuling shale gas field and its enlightenment and thinking. Earth Science Frontiers 2016, 23(1): 29-43. (in Chinese) 
Guo, X.S. Enrichment Mode and Exploration Technology in Jiaoshiba Area of Fuling Shale Gas Field. Beijing, Science Press, 2014. (in Chinese)

Guo, X.S., Hu, D.F., Wei, X.F., et al. Main controlling factors on shale fractures and their influences on production capacity in Jiaoshiba area, the Sichuan Basin. Oil \& Gas Geology 2016, 37(6): 799-808. (in Chinese)

Hao, F., Guo, T.L., Zhu, Y.M., et al. Evidence for multiple stages of oil cracking and thermochemical sulfate reduction in the Puguang gas feld, Sichuan Basin, China. AAPG Bull. 2008, 92(5): 611-637.

Hao, F., Zou, H.Y. Cause of shale gas geochemical anomalies and mechanisms for gas enrichment and depletion in high-maturity shales. Mar. Pet. Geol. 2013a, 44: 1-12.

Hao, F., Zou, H.Y, Lu, Y.C. Mechanisms of shale gas storage: Implications for shale gas exploration in China. AAPG Bull. 2013b, 97(8): 1325-1346.

Haydel, J.J., Kobayashi, R. Adsorption equilibria in methanepropane-silica gel system at high pressures. Ind. Eng. Chem. Fundam. 1967, 6: 564-554.

Ji, W.M., Song, Y., Jiang, Z.X., et al. Geological controls and estimation algorithms of lacustrine shale gas adsorption capacity: A case study of the Triassic strata in the southeastern Ordos Basin, China. Int. J. Coal Geol. 2014, 134: 61-73.

Jiang, Z.X., Tang, X.L., Li, Z., et al. Pore structure and gas-bearing properties of typical marine and continental shale reservoirs in China. Beijing, Science Press, 2018. (in Chinese)

Jin, Z.J., Nie, H.K., Liu, Q.Y., et al. Source and seal coupling mechanism for shale gas enrichment in upper Ordovician Wufeng Formation-Lower Silurian Longmaxi Formation in Sichuan Basin and its periphery. Mar. Pet. Geol. 2018, 97: 78-93.

Kim, J., Kim, D., Lee, W., et al. Impact of total organic carbon and specific surface area on the adsorption capacity in Horn River Shale. J. Pet. Sci. Eng. 2017, 149: 331-339.

Langmuir, I. The adsorption of gases on plane surfaces of glass, mica and platinum. J. Am. Chem. Soc. 1918, 40(9): 1361-1403.

Lewis, R., Ingraham, D., Pearcy, M., et al. New evaluation techniques for gas shale reservoirs. In: Schlumberger Reservoir Symposium, Denver, Colorado, July 29-20, 2004.

Li, A.F. Reservoir Physics. 3nd Ed. Dongying, China University of Petroleum Press, 2015. (in Chinese)

Li, J., Wu, Q.Z., Lu, J., et al. To quantitatively determine the adsorption and free methane volume content in shale gas core based on NRM technique. Well Logging Technology 2018, 42(3): 315-320. (in Chinese)

Li, W.G., Yang, S.L., Xu, J., et al. A new model for shale adsorptive gas amount under a certain geological conditions of temperature and pressure. Natural Gas
Geoscience 2012, 23(4): 791-796. (in Chinese)

Ma, Y., Zhong, N.N., Li, D.H., et al. Organic matter/clay mineral intergranular pores in the Lower Cambrian Lujiaping Shale in the north-eastern part of the upper Yangtze area, China: A possible microscopic mechanism for gas preservation. Int. J. Coal Geol. 2015, 137: 38-54.

Qi, Y., Ju, Y.W., Huang, C., et al. Influences of organic matter and kaolinite on pore structures of transitional organicrich mudstone with an emphasis on S2 controlling specific surface area. Fuel 2019, 237: 860-873.

She, X.Y., Chen, J., Zhang, S.W., et al. Tectonic characteristics and their shale gas geological significance of the Mesozoic-Paleozoic in Jiaoshiba area, the Sichuan Basin. Oil \& Gas Geology 2016, 37(6): 828-837. (in Chinese)

Standing, M.B., Katz, D.L. Density of natural gases. Trans. AIME 1942, 146: 140-149.

Tang, H.M., Wang, J.J., Zhang, L.H., et al. Testing method and controlling factors of specific surface area of shales. J. Pet. Sci. Eng. 2016, 143: 1-7.

Tang, Y., Li, L.Z., Jiang, S.X. A logging interpretation methodology of gas content in shale reservoirs and its application. Natural Gas Industry 2014, 34(12): 46-54. (in Chinese)

Wang, F.Y., Guan, J., Feng, W.P., et al. Evolution of overmature marine shale porosity and implication to the free gas volume. Pet. Explor. Dev. 2013, 40(6): 819-824.

Wang, F.Y., He, Z.Y., Meng, X.H., et al. Occurrence of shale gas and prediction of original gas in-place (OGIP). Natural Gas Geoscience 2011, 22(3): 201-510. (in Chinese)

Yang, F., Ning, Z.F., Zhang, R., et al. Investigations on the methane sorption capacity of marine shales from Sichuan Basin, China. Int. J. Coal Geol. 2015, 146: 104-117.

Yang, W.X., Li, J.Q., Gou, Q.F. Experiment study on shale adsorption properties for Jiaoshiba shale, Sichuan Basin. Natural Gas Geoscience 2017, 28(9): 1350-1355. (in Chinese)

Zhang, T.W., Ellis, G.S., Ruppel, S.C., et al. Effect of organicmatter type and thermal maturity on methane adsorption in shale-gas systems. Org. Geochem. 2012, 47(6): 120131.

Zhang, X.M., Shi, W.Z., Shu, Z.G., et al. Calculation model of shale gas content and its application in fuling area. Earth Science 2017, 42(7): 1157-1168. (in Chinese)

Zhao, H., Givens, N.B., Curtis, B. Thermal maturity of the Barnett Shale determined from well-log analysis. AAPG Bull. 2007, 91(4): 535-549.

Zhao, J.Z., Shen, C., Ren, L., et al. Quantitative prediction of gas contents in different occurrence states of shale reservoirs: A case study of the Jiaoshiba shale gasfield in the Sichuan Basin. Natural Gas Industry 2017, 37(4): 19-25. (in Chinese) 